\title{
Intracrystalline deformation and nanotectonic processes in magnetite from a naturally deformed rock
}

\author{
Manish A. Mamtani ${ }^{\mathrm{a}, *}$, Boris Reznik ${ }^{\mathrm{b}}$, Agnes Kontny ${ }^{\mathrm{b}}$

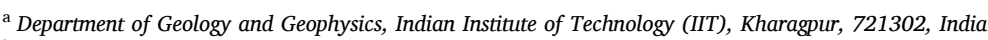 \\ ${ }^{\mathrm{b}}$ Institute of Applied Geosciences, Karlsruhe Institute of Technology (KIT), D-76131, Karlsruhe, Germany
}

Keywords:

Magnetite

Deformation mechanism

SEM-EBSD

TEM

Nanotectonics

Magnetic anisotropy

\begin{abstract}
A B S T R A C T
Although experimental studies have shown dislocation creep to be an important deformation mechanism in magnetite at medium to high temperature, evidence of intracrystalline deformation in magnetite remains to be established in natural tectonically deformed rocks. In this study we investigate intracrystalline deformation features and nanostructures in elongated magnetite from a naturally deformed rock (mylonitized mica schist deformed in a large-scale shear zone of the Seve nappe, Swedish Caledonides). The magnetite grains have very high aspect ratios (up to 10.40) that result in very high degree of magnetic anisotropy in the rock. We show low and high angle grain boundaries (LAGB and HAGB) in magnetite using a combination of electron backscatter diffraction and high-resolution transmission electron microscopy (HRTEM) analysis. HRTEM studies on lamellae excavated perpendicular to the LAGB and HAGB reveal translational and rotational Moiré fringes, respectively. Dislocations, slip bands, stacking faults, twins and recrystallized domains are observed in the vicinity of the grain boundaries, thus providing unequivocal evidence of intracrystalline deformation of magnetite. Our study also reveals the presence of biotite inclusions intergrown epitaxially with magnetite that show no evidence of lattice defects, thus suggesting that the intracrystalline deformation of magnetite took place under wet conditions. The movement at the grain boundaries is interpreted as a response to regional tectonics with a top-to-NW transport direction. It is established that at the nanoscale, the LAGB and HAGB were favourably oriented to accommodate strain dominantly by translation and rotation, respectively. Thus, the nanotectonic processes are consistent with the regional tectonic reference frame. The importance of evaluating ductile behaviour of magnetite from deformed polymineralic rocks in petrofabric analysis and modeling the relation between strain and rock magnetic anisotropy is discussed.
\end{abstract}

\section{Introduction}

In the past few decades there is increasing use of various magnetic methods, particularly anisotropy of magnetic susceptibility (AMS) for petrofabric analysis that provides greater information about rock deformation, strain and tectonics (e.g., Graham, 1954; Tarling and Hrouda, 1993; Bouchez, 1997; Borradaile and Jackson, 2010; Mamtani, 2014 amongst others). Magnetite is a common accessory mineral in many crustal rocks on earth and an important ore mineral. It is also the most important ferromagnetic (s.l) mineral in rocks that dominates the magnetic susceptibility and anisotropy (e.g., Tarling and Hrouda, 1993; Borradaile and Jackson, 2010). Hence, understanding the deformation behavior of magnetite can significantly improve the interpretation of anisotropy of magnetic susceptibility (AMS) in magnetite-bearing rocks.
Active versus passive rigid rotation models (e.g. Tarling and Hrouda, 1993; Mamtani et al., 2011), plastic deformation (e.g. Housen et al., 1995; Ferré et al., 2003) and synkinematic anisotropic crystal growth (Kontny et al., 2012) have been proposed to explain the magnetic anisotropy produced by magnetite. Petrographic studies have confirmed that magnetite mimics the fabric of para- and diamagnetic phases in deformed polymineralic rocks (e.g., Archanjo et al., 1995; Sen and Mamtani, 2006; Mamtani et al., 2011, 2013), and magnetite grains with high aspect ratio produce a high degree of magnetic anisotropy due to shape preferred orientation (e.g. Kontny et al., 2012). Flow laws for magnetite predict that intracrystalline deformation by dislocation creep is the most important deformation mechanism at moderate to high temperature (Atkinson, 1977; Housen et al., 1995; Till and Moskowitz, 2013). Deformation experiments have also revealed that magnetite may

\footnotetext{
* Corresponding author.

E-mail address: mamtani@gg.iitkgp.ac.in (M.A. Mamtani).
} 

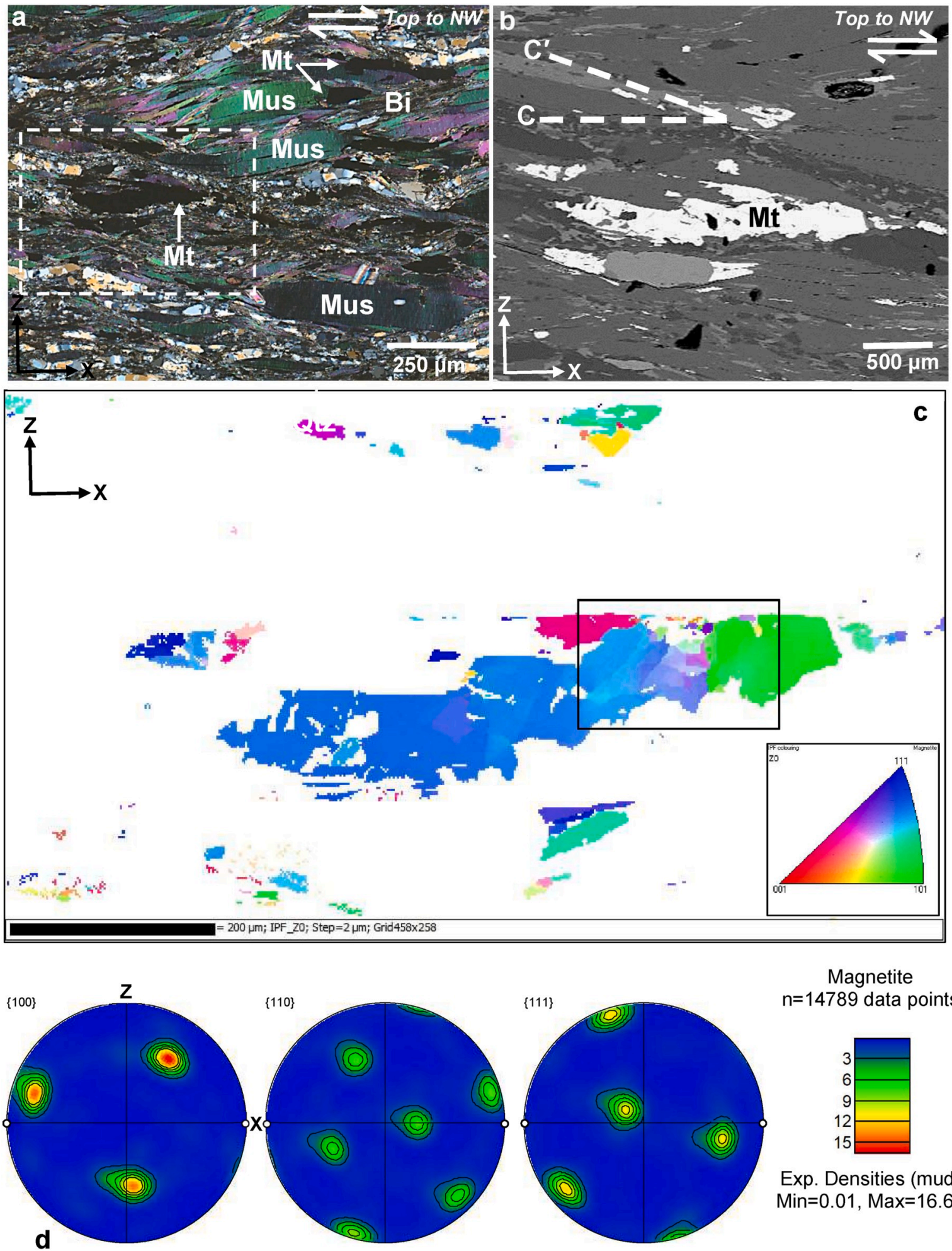

Magnetite $n=14789$ data points

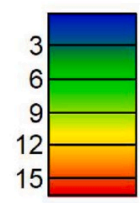

Exp. Densities (mud) Min=0.01, Max=16.62

Fig. 1. Microstructures in the mylonitized magnetite bearing garnet mica schist from the Slipsiken Shear Zone (Sweden) investigated in the present study. (a) Photomicrograph (crossed polarizers) showing the presence of muscovite (Mus), quartz (Qtz), biotite (Bi) and magnetite (Mt). Dashed box in (a) demarcates the area investigated under SEM the image of which is shown in (b). Note the presence of muscovite fish as well as magnetite showing a fish-like geometry. (b) Backscatter Electron (BSE) image showing shear bands (C-C' fabric) adjacent to magnetite (Mt) in the mylonitized schist showing a top-to-NW sense of shear. The magnetite marked "Mt" is the focus of detailed SEM-EBSD and TEM investigations in this study. (c) Inverse Pole Figure map (2 $\mu \mathrm{m}$ step size) of the large magnetite marked "Mt" in (b) along with smaller magnetite grains in its vicinity. The box demarcates the part of magnetite grain that was investigated in detail under SEM and TEM. (d) Pole figures (lower hemisphere equal area projections) of [100], [110] and [111] crystallographic axis of magnetite in (c). 
undergo intracrystalline deformation by twinning and slip even at relatively low temperature $\left(200\right.$ and $\left.400{ }^{\circ} \mathrm{C}\right)$ and at high strain rates $\left(3 \times 10^{-6} \mathrm{~s}^{-1}\right.$; Müller and Siemes, 1972; Hennig-Michaeli and Siemes, 1975, 1982). Till et al. (2012) and Till and Moskowitz (2013, 2014) performed high-temperature $\left(1000^{\circ}-1200{ }^{\circ} \mathrm{C}\right)$ laboratory shear experiments at high strains (up to $300 \%$ ) on a synthetic mixture of magnetite (3\%) and plagioclase cold-pressed pellets, and studied the deformed magnetite using AMS, shape-preferred orientation (SPO) and electron backscatter diffraction (EBSD). Magnetic anisotropy and SPO were observed to increase with strain, and also subgrains were identified from EBSD studies, implying intracrystalline deformation by dislocation creep. Transmission Electron Microscopy (TEM) studies have helped to recognize and further characterize nanostructures in magnetite like stacking faults in lodestone (Banfield et al., 1994), dislocation networks at grain contacts with other mineral phases in granulite-facies marble (Sitzman et al., 2000), dislocations and twins in experimentally deformed sample cut from magnetite octahedron (Lindquist et al., 2015, 2019), as well as kinks and twins in magnetite in experimentally shocked banded iron ore (Reznik et al., 2016).

However, unlike experimental studies, the response of magnetite to strain in naturally deformed polymineralic rocks remains poorly understood. EBSD studies of magnetite in the Godhra Granite (India) known to have emplaced syntectonically and developed hightemperature solid-state deformation fabrics (Mamtani and Greiling, 2005,2010 ) did not show any evidence of intracrystalline deformation, while the matrix minerals (quartz, feldspar, ilmenite etc.) were replete with subgrain microstructures (Mamtani et al., 2011). Likewise, EBSD studies of magnetite in mylonitized garnet-mica schist from the Swedish Caledonides did not reveal any evidence of intracrystalline deformation by dislocation creep despite the rock having experienced high- $\mathrm{T}$ deformation $\left(670 \pm 50^{\circ} \mathrm{C}\right.$; Grimmer et al., 2015). These schists also showed very high magnetic anisotropy ( $>3.9$ ) as well as unusual field dependence of magnetic susceptibility of up to $10 \%$ in the direction of the maximum principal axis of the AMS ellipsoid $\left(\mathrm{K}_{\max }\right)$.

Thus, several questions remain un-answered in naturally deformed magnetite - (a) does it develop sub-grains, such as the ones observed in experiments of Till and Moskowitz (2014)? (b) Can different types of grain boundaries (low/high angle) be recognized in magnetite? (c) What are the nanostructures at grain boundaries in magnetite? (d) What are the processes that may be active at different grain boundaries within magnetite? The present investigation addresses these questions. Since magnetite is opaque under the optical microscope and intracrystalline deformation features cannot be identified using reflected-light microscopy, these questions can be addressed only through a systematic electron microscopic study. Therefore, we present microscale (SEM-EBSD) and nanoscale (HRTEM) data, which provide evidence for low- and high-angle grain boundaries (LAGB and HAGB) in elongated magnetite grains from the mylonitized garnet-mica schist from the Slipsiken Shear Zone (SSZ, Sweden) investigated earlier by Kontny et al. (2012). We discuss the implications of these intracrystalline deformation features on petrofabrics and strain, particularly with respect to magnetic anisotropy.

\section{Material and methods}

\subsection{Sample description}

The SSZ is regarded as a lithosphere-scale roof shear zone of an extrusion wedge whose regional geology and tectonics (including AMS, petrology and geochronology) is described in Kontny et al. (2012) and Grimmer et al. (2015). Top-to-NW shearing occurred at temperature $\geq 550{ }^{\circ} \mathrm{C}$ and the schists are known to contain pure magnetite (Kontny et al., 2012). The sample used in this study (SS-16a) has very high magnetic susceptibility (up to $97 \times 10^{-3}$ SI units) and magnetic anisotropy (P values ranging from 3.9 to 4.2 ). The NW-SE striking mylonitic foliation has a gentle northeasterly dip, and carries a sub-horizontal stretching lineation. For this study, a XZ thin section was prepared parallel to the NW-SE oriented stretching lineation and perpendicular to the foliation.

\subsection{SEM-EBSD analysis}

Electron backscatter diffraction (EBSD) analysis was done on thin sections which were polished for $\sim 10 \mathrm{~h}$ with non-crystalline colloidal silica solution and subsequently coated with a $5 \mathrm{~nm}$ thick carbon layer. EBSD patterns were acquired at $30 \mathrm{kV}$ accelerating voltage, $1.49 \times 10^{-6}$ mbar system vacuum, and $\sim 14 \mathrm{~mm}$ working distance using Carl Zeiss Auriga Compact FEG-SEM fitted with NordlysMax2 EBSD detector (Oxford instruments, UK) housed in the Central Research Facility of IIT Kharagpur (India). Data acquisition and indexing of EBSD patterns were carried out automatically using AZtec software (Oxford instruments, UK). $97 \%$ of indexing (hit rate) was achieved during mapping/data acquisition of individual magnetite grains. The acquired data were processed using HKL CHANNEL 5 software (Oxford Instruments, UK). A low-level noise reduction was performed, which involved replacement of non-indexed solutions by the most common neighbour orientations. Subsequently, Inverse Pole Figure (IPF) maps and pole figures (lower hemisphere equal area projections) of [100], [110] and [111] crystallographic axes of magnetite were prepared. Misorientation profiles were prepared across selected areas where variations in crystallographic orientations could be visually identified in IPF maps. In this study, misorientation $\leq 10^{\circ}$ is designated as Low Angle Grain Boundary (LAGB) and $>10^{\circ}$ as High Angle Grain Boundary (HAGB).

\subsection{FIB sample preparation and TEM analysis}

Lamellae for investigation under TEM were prepared using focused ion beam (FIB) milling station FEI DualBeam Strata 400S with a gallium $(\mathrm{Ga}+)$ source housed in the Laboratory for Electron Microscopy (LEM) of Karlsruhe Institute of Technology (Germany). Prior to loading the thin section in the SEM, it was coated with platinum. Following the standard FIB procedure under SEM (e.g. Heaney et al., 2001), a platinum strap $(\sim 1 \mu \mathrm{m}$ thick) was deposited on the region of interest. Lamellae were prepared using a $30 \mathrm{kV}, 6.5 \mathrm{nA}$ gallium ion beam. In the present study, two lamellae, one across the LAGB, and another across the HAGB were excavated; it maybe noted that these grain boundaries were identified based on EBSD studies (section 3.2). Each excavated lamella was mounted on an individual FIB Lift-Out TEM grid (Copper, 2 posts) and further thinned to $\sim 50 \mathrm{~nm}$ using a $30 \mathrm{kV}, 26 \mathrm{pA}$ gallium ion beam. As a final step, the sample was polished and cleaned with a $5 \mathrm{kV}$ (71 pA ion current) to remove any damaged crust that may have been induced by the high energy ion beam.

The TEM study was done using a Philips CM 200 FEG/ST TEM operated at $200 \mathrm{kV}$ (LEM, KIT Karlsruhe, Germany). A condenser aperture of $100 \mu \mathrm{m}$ at a spot size of $\geq 300 \mathrm{~nm}$ was used for selected area electron diffraction (SAED) and general TEM investigations. Low- and high-resolution TEM (HRTEM) imaging was done using various modes including bright field, dark field as well as weak beam dark field conditions (Williams and Carter, 2009). Fast Fourier Transformation of HRTEM images was performed using ImageJ software (www.imagej. nih.gov/ij).

\section{Results}

\subsection{Petrography}

Petrographic studies establish that the investigated mica schist is rich in muscovite and dynamically recrystallized quartz (Fig. 1a). Feldspar, biotite and garnet (porphyroblasts) are also present while magnetite occurs as an accessory mineral phase. As shown in Fig. 1a and b, in this mylonitized rock, muscovite forms prominent fish-like geometries and shear band $\mathrm{C}-\mathrm{C}^{\prime}$ fabrics are well-developed. As stated earlier, the 

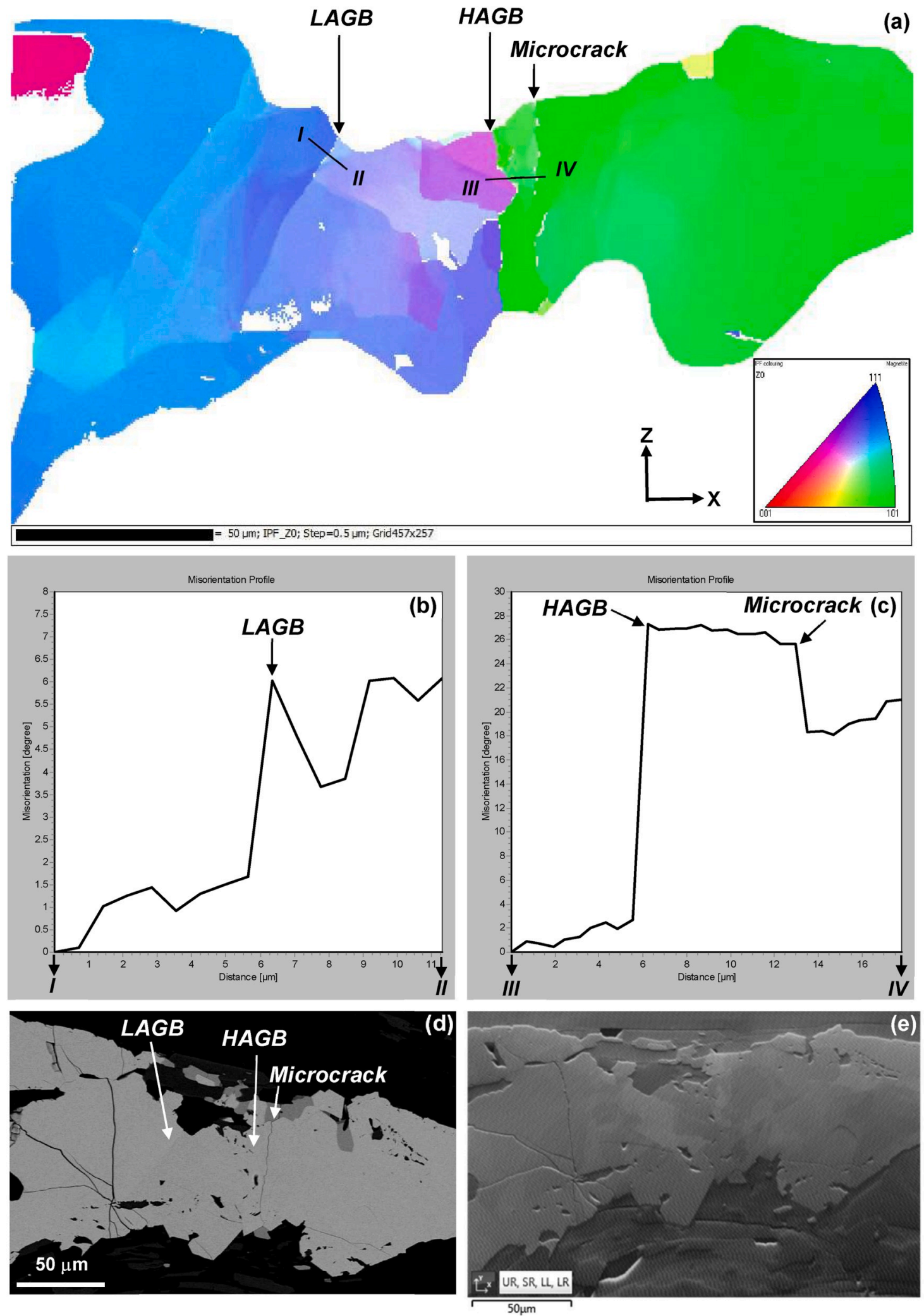

Fig. 2. High resolution SEM-EBSD data of magnetite from the area demarcated by the box in Fig. 1c. (a) IPF map (0.5 $\mu \mathrm{m}$ step size) showing crystallographic variation that implies intracrystalline deformation (also see supplementary data-2 to compare the mapped boundary of magnetite superimposed on the complete magnetite grain). LAGB and HAGB refer to Low Angle Grain Boundary and High Angle Grain Boundary of magnetite, respectively (see text for details). I-II and III-IV are the lines along which misorientation profiles of magnetite CPO have been plotted in (b) and (c), respectively. Misorientation along I-II is measured with reference to orientation at I. Misorientation along III-IV is measured with reference to orientation at III. LAGB and HAGB correspond to their respective position shown in (a). (d) BSE image of the investigated magnetite showing position of LAGB, HAGB and microcrack. (e) Forescatter detector (FSD)/orientation contrast (OC) image of the magnetite indicating presence of subgrains in magnetite. See Fig. 3 for higher magnification SEM images of LAGB and HAGB. 


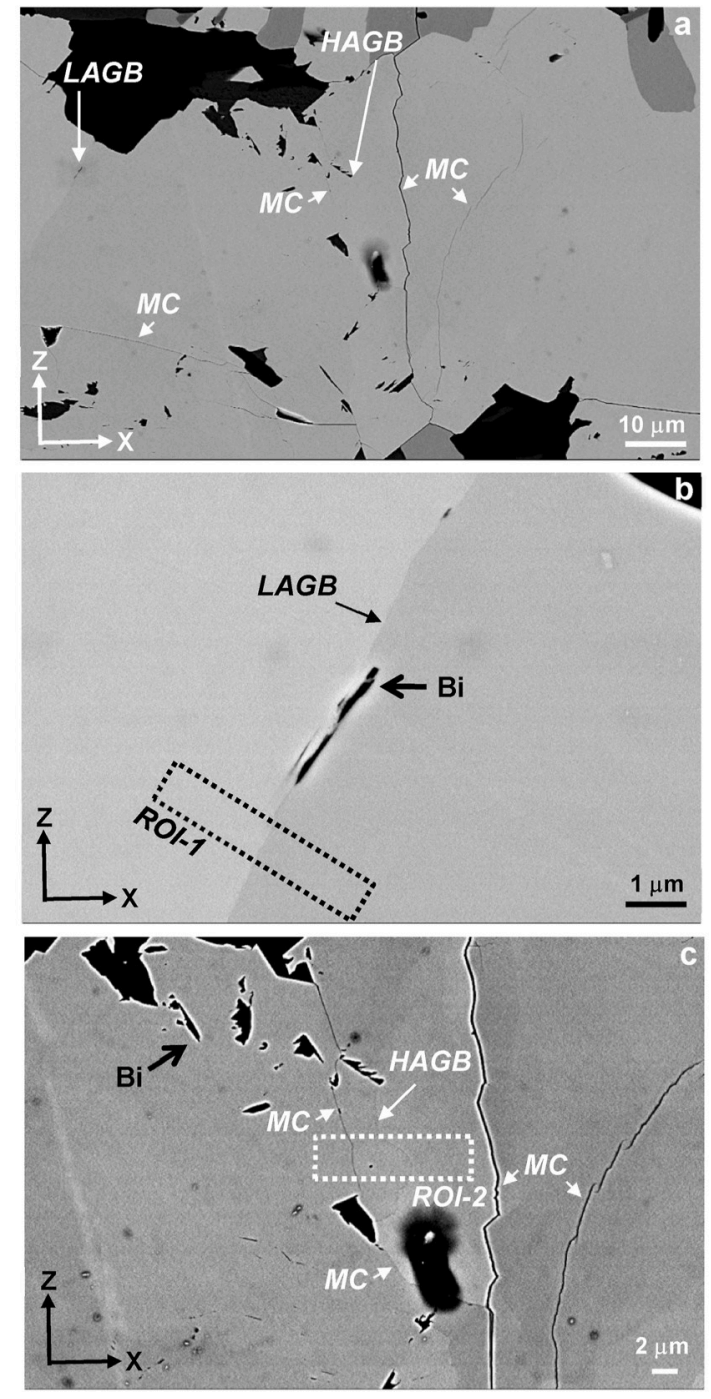

Fig. 3. SEM images of the investigated magnetite (a) High magnification SEM images of the area of interest within the magnetite grain showing LAGB and HAGB. The microcracks are demarcated by arrows marked "MC". Note the absence of microcracks in the vicinity of the LAGB. The dark particles at the grain boundaries are biotite $(\mathrm{Bi})$. All images are in the $\mathrm{XZ}$ reference frame of the strain ellipsoid (compare with Fig. 4). The broad region of interest (ROI) for TEM studies is marked ROI-1 across the LAGB in (b), and ROI-2 across the HAGB in (c). Note that ROI-1 and ROI-2 comprise profile I-II and III-IV, respectively. Lamellae for TEM analyses were prepared from these ROI using Focused Ion Beam (FIB) technique under SEM.

investigated section was prepared parallel to the stretching lineation and perpendicular to the foliation. Accordingly, the inferred sense of shear is top-to-NW, which is in agreement with the regionally known kinematics (Kontny et al., 2012; Grimmer et al., 2015). Some of the elongated magnetite grains such as the one marked Mt in Fig. 1a and b also have a "fish" like shape. The grain size of the magnetite, measured as equal area diameter, varies between $24 \mu \mathrm{m}$ and $104 \mu \mathrm{m}$, and their aspect ratio varies between 1.06 and 10.40 . The present study integrating EBSD and TEM analysis is focused on the elongated magnetite grain labeled "Mt" in Fig. 1b.

\subsection{EBSD analysis}

The acquisition of magnetite EBSD data was done with $2 \mu \mathrm{m}$ step size on a relatively large area (ca. $0.5 \mathrm{~mm}^{2}$ frame area) in order to identify sectors in magnetite grains that may show evidence of crystallographic variation. Fig. 1c is the IPF map of magnetite in Fig. 1b (also see Supplementary Data-1 for IPF map of other magnetite grains from Fig. 1a). Pole figures of [100], [110] and [111] crystallographic axes of magnetite show a strong CPO for this grain (Fig. 1d). However, some variations in crystallographic axis orientation in a part of the large magnetite grain strongly suggest the presence of (sub)grain boundaries. The area boxed in Fig. 1c was chosen for EBSD data acquisition and mapping at higher magnification and lower step size $(0.5 \mu \mathrm{m})$. In order to avoid mapping of any other phase, the approximate boundary of the magnetite grain was outlined using the AZtec software; the obtained IPF map is presented in Fig. 2a (see also Supplementary Data-2 for detailed modus operandi). Crystallographic misorientations were measured along two profiles I-II and III-IV shown in Fig. 2a. The misorientation across profile I-II is $\sim 6^{\circ}$ (Fig. 3d), which corresponds to a LAGB, while the misorientation across profile III-IV is significantly larger $\left(\sim 26^{\circ}\right.$; Fig. $3 \mathrm{c}$ and d), in agreement with a HAGB.

Mamtani et al. (2011) documented that crystallographic variation of $\sim 4^{\circ}$ in a magnetite from the Godhra Granite (India) occurred across microcracks and hence it was inferred to be on account of brittle deformation rather than ductile/intracrystalline deformation. In this magnetite from SSZ (Sweden), no evidence of microcrack is noted under SEM at the LAGB (Fig. 2d and e and Fig. 3a and b). Hence, the low angle crystallographic misorientation in this magnetite can be considered as a good evidence of intracrystalline deformation. This is also implied from the orientation contrast (OC) image (Fig. 2e). On this basis, we can infer that the magnetite grain investigated under SEM shows presence of subgrains.

The LAGB is ornamented by fine biotite crystals ( $\sim 3 \mu \mathrm{m}$; Fig. 3a and b) as confirmed by SEM-EDX analysis. Larger biotite crystals ( $>5 \mu \mathrm{m})$ are present in the vicinity of the HAGB and microcracks (arrows marked MC in Fig. 3a,c) are noted close to it. A high magnification SEM image of the HAGB that was identified from EBSD studies (profile III-IV in Fig. 2a) is shown in Fig. 3c. In order to further investigate the deformation features and nanostructures as well as the processes at grain boundaries, we performed a TEM analysis. The region of interest (ROI) across the LAGB and HAGB is boxed, respectively, as ROI-I (Fig. 3b) and ROI-II (Fig. 3c). Note that these regions of interest are the same across which misorientation profiles I-II and III-IV, respectively, have been prepared using EBSD data (compare locations of profiles in Fig. 2a with ROI in Fig. 3).

\subsection{TEM studies}

Fig. 4a illustrates the reference frame for the thin section from which the FIB lamellae for TEM investigations were excavated. Two lamellae, one across the LAGB (FIB Lamella-1, Fig. 4b) and another across the HAGB (FIB Lamella-2, Fig. 4c) were excavated. SEM images of the two lamellae are presented in the tectonic reference frame in Fig. $4 \mathrm{~b}$ and c. Comparison of Fig. 4 with Figs. 2 and $3 \mathrm{~b}$ and c provides the reader with a complete correlation between misorientation profiles, ROI and FIB lamellae. LAGB is clearly visible in FIB Lamella- 1 and across it, the magnetite subgrains are marked M1 and M2 (Fig. 4b). Similarly, HAGB is also clearly identified in the SEM image of FIB Lamella-2 (Fig. 4c; magnetite subgrains marked M3, M4, M5). In addition, a biotite crystal is also identified at the HAGB (marked Bi in Fig. 4c); this boundary between biotite and magnetite defines a phase boundary.

\subsubsection{Nanostructures across LAGB}

We looked at the M1/M2 interface (LAGB) in FIB Lamella-1 under the TEM. The nanostructures observed at low and medium magnifications are presented in Fig. 5. After adjusting M1 to the [110] zone axis, a strong orientation contrast between M1 and M2 subgrains is visible (Fig. 5a). Under dark field imaging conditions (Fig. 5b), slip bands oriented parallel to [110] can be recognized (Fig. 5b). Furthermore, ca. 14 $\mathrm{nm}$ thick transition zone can be faintly recognized at this interface. At a higher magnification, using weak beam dark field imaging conditions, 


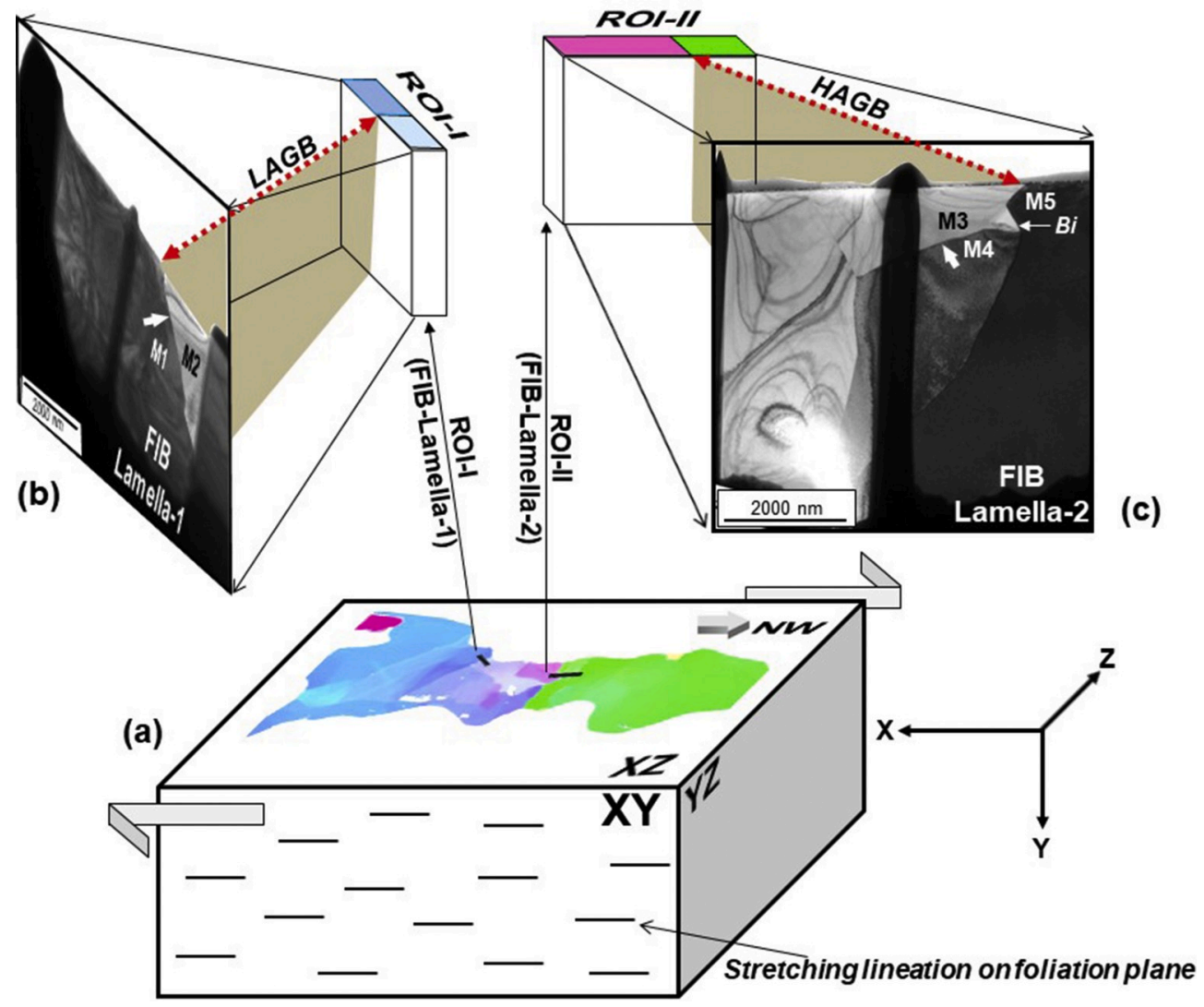

Fig. 4. (a) Schematic block diagram showing the orientation of the magnetite grain as well as the FIB-lamellae in the geographic and regional kinematic reference frame. The block (not-to scale) represents the mylonitized schist sample (SS-16a) with NW-SE striking foliation (XY plane of the strain ellipsoid) containing a stretching lineation (X direction) that has top-towards-NW sense of movement. The thin section investigated in this study is XZ section of the strain ellipsoid and the IPF map of magnetite grain studied here from EBSD studies is represented on the $\mathrm{XZ}$ section of the block diagram presented as Fig. 4a. FIB Lamella-1 (b) and Lamella-2 (c) were excavated from ROI-1 (containing profile I-II) and ROI-2 (containing profile III-IV), respectively (compare with Fig. 3b and c). Thick white arrow in Lamella-1 (b) and Lamella-2 (c) are the LAGB and HAGB, respectively, that have been investigated in detail under TEM. Magnetite subgrains on either side of LAGB are labeled M1 and M2 in (b). Similarly, M3, M4 and M5 are magnetite subgrains at the HAGB in (c). Phase boundary between Biotite (Bi) crystal in (c) and magnetite (M4) has also been investigated. It maybe noted that in both the lamellae, the plan view is XZ section of the strain ellipsoid. The profile of FIB Lamella- 1 is oblique to $\mathrm{XY}$ plane, while the profile of FIB Lamella-2 is parallel to the $\mathrm{XY}$ plane of the stain ellipsoid. The reader may recall this reference frame while viewing Fig. 10. the transition zone appears as Moiré fringes indicating superposition of two overlapping lattices (Fig. $5 c$ and d). Such fringes are known to form due to overlapping of two different crystal lattices associated with translation and/or rotation (e.g., Mitsuishi et al., 1951; Hillier, 1954; McLaren, 1991; Williams and Carter, 2009). This transition zone comprises fringes having periods of ca. $4.5 \mathrm{~nm}$ with some parts also showing evidence of slip (dashed circle, Fig. 5d). At a higher magnification, using Fast Fourier Transformation (FFT) diffraction (see insets in Fig. 6a), we measured the misorientation angle between the M1/M2 interface. The misorientation is $\sim 6^{\circ}$, which is similar to that obtained from the EBSD misorientation profile across the LAGB (Fig. 2b). HRTEM imaging across the $\mathrm{M} 1 / \mathrm{M} 2$ interface reveals polygonal domains in the area of M2, characterized by $120^{\circ}$ triple junctions (Fig. 6a and b). In addition, certain domains show blurred contrast in the HRTEM image (e.g. domain boxed in Fig. 6b), which is an indication of distorted atomic planes. An inverse (002)-FFT image of such domains (inset in Fig. 6b) confirms the presence of dislocations.

\subsubsection{Nanostructures across $H A G B$}

We investigated the HAGB (FIB Lamella-2; Fig. 4c) under TEM to observe the nanoscale structures across it. Fig. 7a is an overview bright field image showing the biotite (Bi) crystal surrounded by magnetite subgrains (M3, M4 and M5). Thus, in addition to studying the magnetite HAGB, FIB Lamella-2 also gave us the opportunity to investigate a magnetite-biotite phase boundary. Similar to the case of the LAGB (Fig. 5b-d), weak beam dark field imaging condition reveals a distinct contrast at the HAGB interface (Fig. $7 \mathrm{~b}$ and $\mathrm{c}$ ). In this case, the transition zone appears as $\sim 30 \mathrm{~nm}$ thick Moiré fringes at the HAGB (M3/M4 interface; Fig. 7b). The geometry is similar to a twisted-ribbon (helicoidal in shape) and implies the interference between crystal lattices by twisting (i.e., torsion) at the HAGB. Following Williams and Carter (2009), this Moiré pattern at the HAGB can be considered to be dominantly rotational in origin.
Fig. 8 presents the results of the HRTEM analysis across the M3/M4 interface (HAGB). The FFT diffractograms (insets in Fig. 8a) from either side of the HAGB establish that the misorientation angle at the HAGB is $\sim 26^{\circ}$. This is in agreement with the misorientation angle recorded in the EBSD misorientation profile for the HAGB (Fig. 2c). A high magnification HRTEM image of the area boxed in Fig. 8a reveals the presence of linear slip bands (marked by dashed line; Fig. 8b) with distorted atomic planes showing blurred contrast in Fig. 8b (inset-i and ii). Defects such as dislocations or stacking faults (inset-i of Fig. 8b) and nano-twins in the magnetite crystal lattice (inset-ii of Fig. 8b) are revealed by the FFT analysis of the blurred domains.

The nanoscale images of the magnetite-biotite phase boundary (M4/ Bi interface of Fig. 7a) is shown in Fig. 9. At this atomic scale, this phase boundary does not show any defects (Fig. 9b). The FFT diffractograms from biotite (Bi) and magnetite (M4) are shown in Fig. 9c and d, respectively. The diffractograms contain three selected diffraction vectors labeled by arrows for which direction and angles are similar in both phases. This implies epitaxial intergrowth of the two phases (magnetite and biotite). This fact is also illustrated by the IFFT images, which show that the orientation of the magnetite and biotite lattice is similar (dashed lines extrapolated across lattice in Fig. 9e and f). In addition, the IFFT images also demonstrate that magnetite contains lattice defects (stacking fault marked SF in Fig. 9f), which is an evidence of deformation. In contrast, biotite has a perfect, defect-free lattice (Fig. 9e).

\section{Discussion}

Unequivocal evidence of intracrystalline deformation in magnetite from naturally deformed polymineralic rocks has rarely been documented. Deformation experiments point to dislocation creep as the main deformation mechanism in magnetite at medium to high temperature (Housen et al., 1995; Till and Moskowitz, 2013). However, neither subgrains nor recrystallization or CPO are reported from magnetite to 

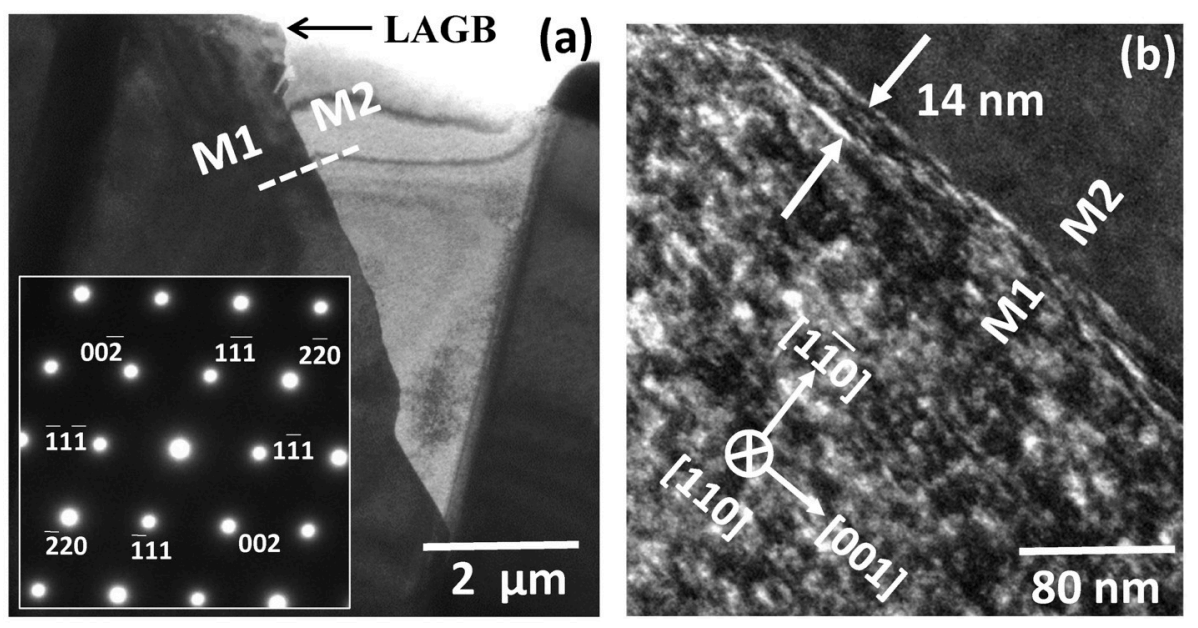

Fig. 5. TEM analysis of a LAGB in FIB Lamella-1. (a) Bright Field image showing overview of the interface (dashed line) between two magnetite subgrains M1 and M2. The inset is a SAED pattern taken from the dark area oriented near to the [110] zone axis. (b) Dark Field image using 220 reflex shows slip bands oriented parallel to [001] direction. The arrows mark ca $14 \mathrm{~nm}$ wide transition zone. (c) The same area as shown in (b) but imaged using weak-beam (111) conditions. Note the well-developed Moiré fringes with alternating spacing and curvature; (d) Enlarged portion of the Moire fringes marked by the white box in (c) showing planar $4.5 \mathrm{~nm}$ thick region (white arrows) and slightly tilted region (dashed circle). See text for details.
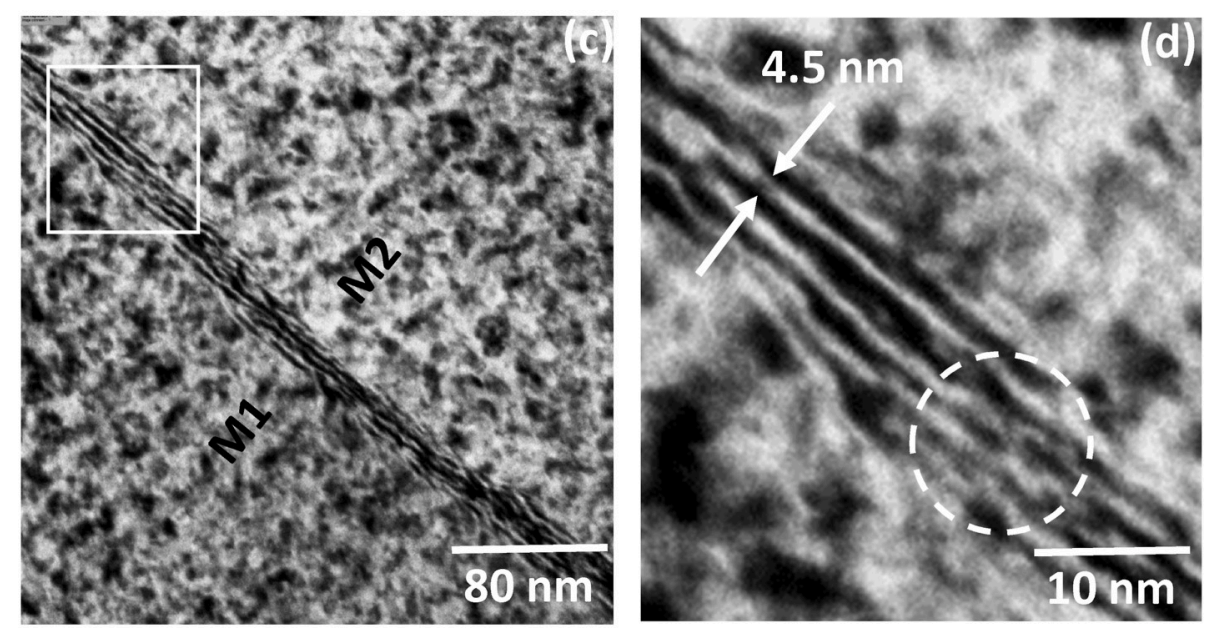

prove dislocation glide in naturally deformed polymineralic rocks (e.g., Mamtani et al., 2011; Kontny et al., 2012). In addition, since a deformation mechanism map is theoretically calculated based on experiments done on single crystals of a mineral, it may not necessarily be valid for that mineral in a polymineralic rock (e.g., Mamtani, 2012). Thus, the present investigation involving microscale (SEM-EBSD) and nanoscale (TEM) studies enables us to evaluate the deformation mechanism of magnetite in polymineralic rocks. This enhances our understanding of the relation between petrofabrics, strain and magnetic anisotropy. All these aspects are discussed in the present section.

\subsection{Dislocation creep in magnetite from tectonically deformed polymineralic rocks}

In an earlier study by Kontny et al. (2012) of the here reinvestigated elongated magnetite grains from the garnet-mica schist of the Slipsiken Shear Zone, no crystal preferred orientation (CPO) of magnetite was observed from EBSD studies performed over the whole thin section. While EBSD for ilmenohematite grains showed a strong CPO due to intracrystalline slip, CPO of magnetite grains was very weak with randomly orientated [111] and [110] axes (Kontny et al., 2012). This lack of CPO in magnetite may be due to the simultaneous activity of multiple glide systems in cubic magnetite as has been experimentally shown by Till and Moskowitz (2014). However, our present high resolution EBSD mapping of an individual elongated magnetite grain shows that there is variation in the crystallographic orientation and that subgrains are present. Based on misorientation profiles, low and high angle grain boundaries (LAGB and HAGB) have been identified where the misorientation across the boundary is $6^{\circ}$ and $26^{\circ}$, respectively.
In a previous SEM-EBSD study of syntectonically deformed Godhra Granite (India; Mamtani et al., 2011), magnetite showed microcracks, while the surrounding matrix minerals (quartz, feldspar, ilmenite) showed subgrains. Mamtani et al. (2011) documented that crystallographic misorientation of $\sim 4^{\circ}$ occurred across microcracks in magnetite, which was attributed to brittle deformation rather than ductile deformation. The results from SEM-EBSD analysis of magnetite in the present study are quite different. Here, the LAGB across which $6^{\circ}$ misorientation is recorded is not associated with any microcrack, and hence the misorientation cannot be attributed to brittle deformation. Contrary to the LAGB, microcracks are indeed present in the vicinity of the HAGB. However, based on the misorientation profile and high resolution SEM imaging (Figs. 2c and 3d) we infer that whilst some of the misorientation can be attributed to microcracks, the misorientation of $26^{\circ}$ cannot be attributed to microcracking.

An unequivocal proof of the ductile behavior of magnetite comes from the TEM data (Figs. 5-9) that confirm the misorientations across the LAGB and HAGB of $6^{\circ}$ and $26^{\circ}$, respectively, which were obtained from the EBSD data (Fig. 2b and c). In addition, the slip bands and the Moiré fringes observed at the LAGB further suggest that the [001] slip direction is combined with a very small rotational component $<10^{\circ}$ of magnetite due to interference of crystal lattice planes. The observed Moiré fringes are considered as dominantly translational since no significant curving or twisting of the fringes is observed (Williams and Carter, 2009). Finally, the presence of polygons in the crystal lattice (Fig. 6) also implies plastic deformation, polygonization, being a recovery mechanism involving movement of dislocations (Spry, 1969; Nicolas and Poirier, 1976).

The thick Moiré fringes of the HAGB with a twisted helicoidal 

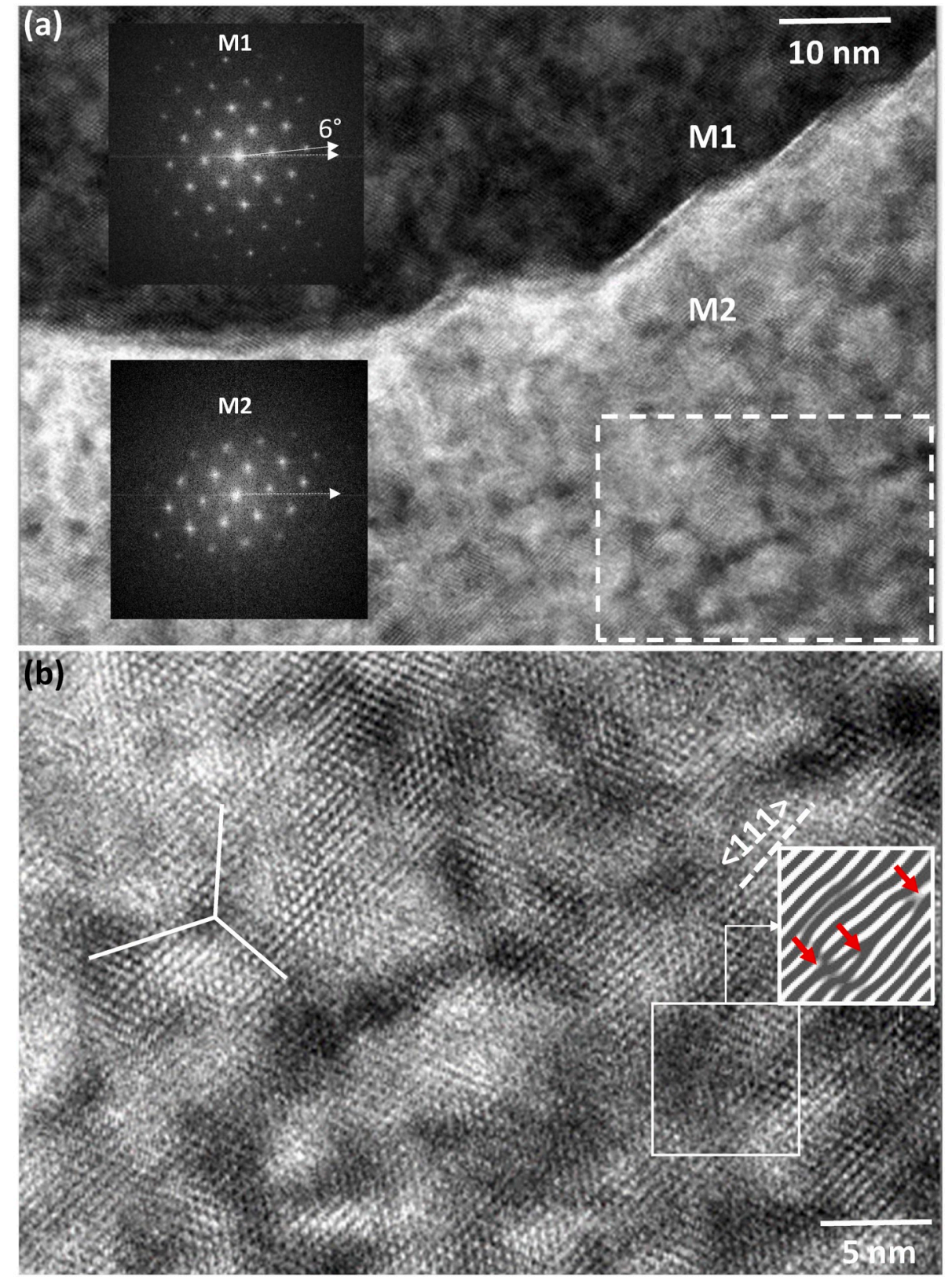

Fig. 6. Nanostructure at the LAGB (M1/M2 interface) described in Fig. 5 (a) Low-magnified HRTEM image with FFT diffractograms (insets) from M1 and M2. According to FFT diffractograms, the misorientation angle across the LAGB is $\sim 6^{\circ}$. Note the presence of polygonal domains (e.g. dashed rectangle; bottom right) (b) HRTEM image of the area marked by the dashed rectangle in (a) shows ordered polygonal domains subdivided by boundaries with $120^{\circ}$ angle triple-junctions (one such triple-junction is marked by white lines; center-left of the image). The white box (lower right) shows a region containing distorted atomic planes exhibiting blurred contrast whose corresponding (002)-IFFT image (inset) reveals dislocations (arrows). geometry implies interference of crystal lattice by twisting at the HAGB. Moreover, presence of linear bands along which slip is recognizable in HRTEM image implies stacking faults, twins and dislocations, all of which are evidences of intracrystalline deformation by dislocation creep in magnetite. We infer that during intracrystalline deformation of magnetite, twisting/torsion was important in causing high misorientation $\left(26^{\circ}\right)$ in parts of the crystal lattice, thus resulting in the development of HAGB. Based on our nanostructural observations we conclude that dislocation creep and subgrain rotation (SGR) were important in the investigated magnetite. Domains where SGR was limited developed LAGB, while those where SGR was strong, evolved into HAGB. In addition, the epitaxial growth between deformed magnetite and undeformed biotite (Fig. 9) indicates that the intracrystalline deformation took place under wet conditions (e.g., Schenk and Urai, 2004). Because the included biotite does not show any signs of deformation (Fig. 9) we suggest that biotite has formed out of a fluid during retrograde mylonitization in the garnet-mica schist.

\subsection{Nanotectonic processes in magnetite in the kinematic reference frame}

As mentioned above, the oriented thin section from which the FIB lamellae have been excavated, is the XZ section of the strain ellipsoid (Fig. 1). Hence, we are able to reconstruct the orientation of the FIB lamellae in the kinematic reference frame (Fig. 4). This in turn allows us to relate the orientation of the grain boundaries (LAGB/HAGB) and comment on the nanotectonic processes along them in this kinematic reference frame. In both the FIB lamellae, the plan view is parallel to the $\mathrm{XZ}$ section of the strain ellipsoid (Fig. 4). However, the profile section of FIB-Lamella-1 is obliquely oriented to XY plane of the strain ellipsoid, while the profile of FIB-Lamella-2 is parallel to the $X Y$ plane. 3D perspective of the magnetite LAGB and HAGB within the FIB lamellae in plan view, as well as profile and some of the nanostructures observed at the respective grain boundaries (under TEM), are presented in Fig. 10.

The sense of shear in the geographic reference frame is known to be top-towards-NW (section 2.1). On plan view, the trace of LAGB is oblique to $\mathrm{X}$ and $\mathrm{Z}$. Nanostructures observed in the FIB-Lamella-1 represent 

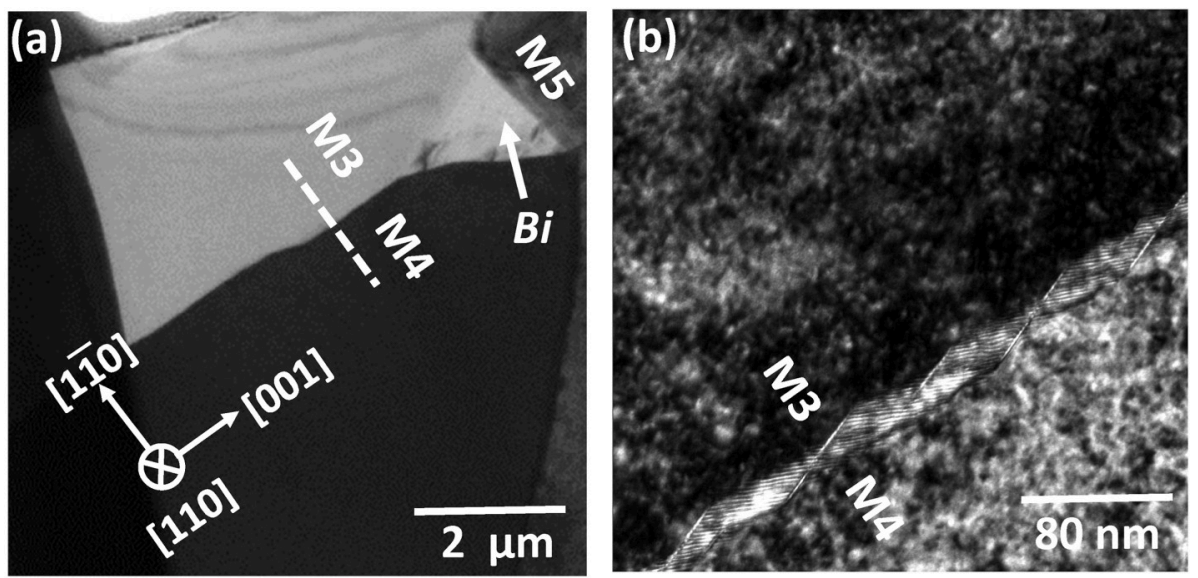

Fig. 7. TEM analysis of the HAGB shown in Fig. 4c. (a) An overview bright field image of the junction area between magnetite (M3, M4, M5) subgrains and biotite (Bi) crystal. Dashed line at the M3/M4 interface marks the area across the magnetite HAGB that was investigated in detail under HRTEM; (b) (111)weak-beam dark field image showing transition zone at the HAGB (M3/M4 interface marked by dashed line in Fig. 7a) exhibiting helix-shaped Moiré fringes. Magnified image of these Moire fringes is shown in (c). Note that compared to the thickness of the transition zone at the LAGB (14 nm in Fig. 5), thickness of the same at HAGB is more than two times larger (30 $\mathrm{nm})$.

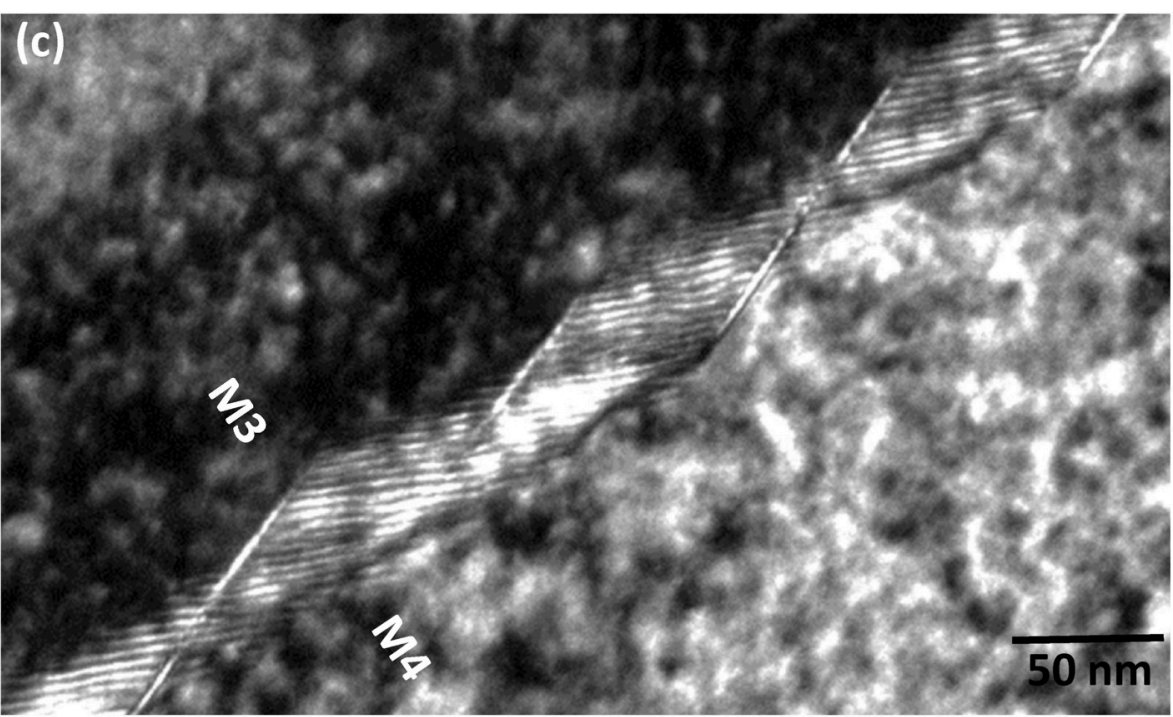

the profile view and the reconstructed 3D perspective of the LAGB is presented in Fig. 10a. Accordingly, the oblique orientation of the LAGB in the kinematic reference frame is favourable to allow slip and hence results in the development of translational Moiré fringes observed under the TEM. On the other hand, the profile of FIB-Lamella-2 is parallel to the $\mathrm{XY}$ plane of the strain ellipsoid and on the plan view (XZ section), the trace of the HAGB is oriented in the $\mathrm{Z}$ direction (Fig. 10b). Rotational Moiré fringes are observed under TEM along the inclined HAGB in the profile section (i.e., FIB- Lamella-2). The twisting movement that can result in the observed geometry of the rotational Moire fringes is clockwise, which is consistent with the top-towards-NW sense of shear deciphered from the XZ section microstructures (Fig. 1). In terms of kinematic evolution, similar phenomena are common at various larger scales e.g. rotation of structures at plate boundaries due to transcurrent movement or rotation of foliation within shear zones (e.g., Carreras, 2001; Platt and Becker, 2013; Hernandez-Moreno et al., 2014). Thus, we conclude that the nanotectonic processes deciphered from the grain boundaries in the magnetite are synchronous to the regional tectonic processes that led to mylonitization of the rock.

\subsection{Deformation mechanism of magnetite and degree of magnetic anisotropy in deformed polymineralic rocks}

The elongated magnetite grains from the Slipsiken Shear Zone under study are responsible for extremely high degrees of magnetic anisotropy (P) up to 4.2 in low-field magnetic susceptibility measurements (Kontny et al., 2012). $P$ is a parameter that quantifies the eccentricity of the AMS ellipsoid (Tarling and Hrouda, 1993). Empirically, variation in P in a particular lithology has been used to gauge strain intensity variations using the logic that higher P implies higher fabric intensity, and hence higher strain (Borradaile and Henry, 1997; Sen et al., 2005; Sen and Mamtani, 2006; Majumder and Mamtani, 2009; Mamtani et al., 2011 amongst others). In the Swedish Caledonides, Kontny et al. (2012) and Merz et al. (2019) have also recognized an increase in magnetic anisotropy with increasing stage of mylonitization. However, in all the above previous studies the influence of deformation mechanism of magnetite on $P$ in naturally deformed rocks has remained un-investigated. This aspect is important because (a) magnetite influences AMS of polymineralic rocks and (b) the behavior of magnetite (brittle or ductile) has a bearing on the magnetic anisotropy (Tarling and Hrouda, 1993).

$P$ in rocks has been empirically demonstrated to be controlled by the rheological behavior of magnetic grains vis-à-vis the matrix and four models viz. passive, ductile, line/plane and viscous have been presented (Owens, 1974; Hrouda and Lanza, 1989; Hrouda, 1993). The passive model assumes no viscosity contrast between magnetic grains and matrix minerals and is not applicable to a natural polymineralic rock system. In the ductile model, both the magnetic and matrix grains are considered to be rheologically different, but both undergo ductile deformation, and P increases with strain. During progressive deformation, this relation (P vs. strain) is dependent on the viscosity contrast between the matrix minerals and the magnetic grains; the lower the viscosity contrast, the faster is the increase in $\mathrm{P}$ with strain and vice versa. The line/plane model assumes that the magnetic grains behave 


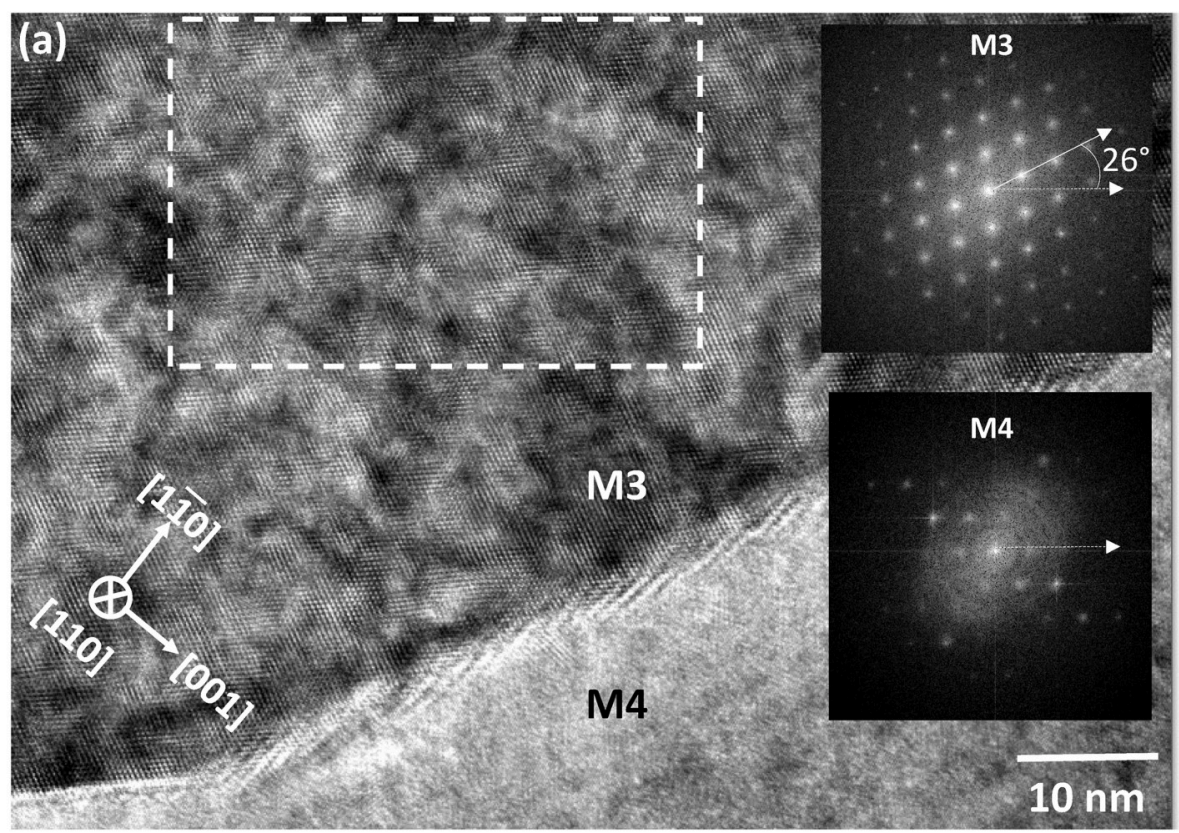

Fig. 8. (a) Low magnification HRTEM image with FFT diffractograms (insets) from M3 and M4 interface (HAGB). According to FFT diffractograms, the misorientation angle across the HAGB is $\sim 26^{\circ}$. Note the presence of obliquely oriented (top left to bottom right) linear bands running parallel to [001] direction. Detailed HRTEM imaging of the area marked by the dashed rectangle was done. The observed nanostructures of this marked area are shown in (b), wherein linear bands (dashed lines) suggest slip within the crystal lattice. The IFFT image displays stacking faults (SF) and dislocations (D) (see inset-i). The same HRTEM image also shows domains with zig-zag atomic arrangement and the IFFT image of the same establishes these as nano-twins (inset-ii).

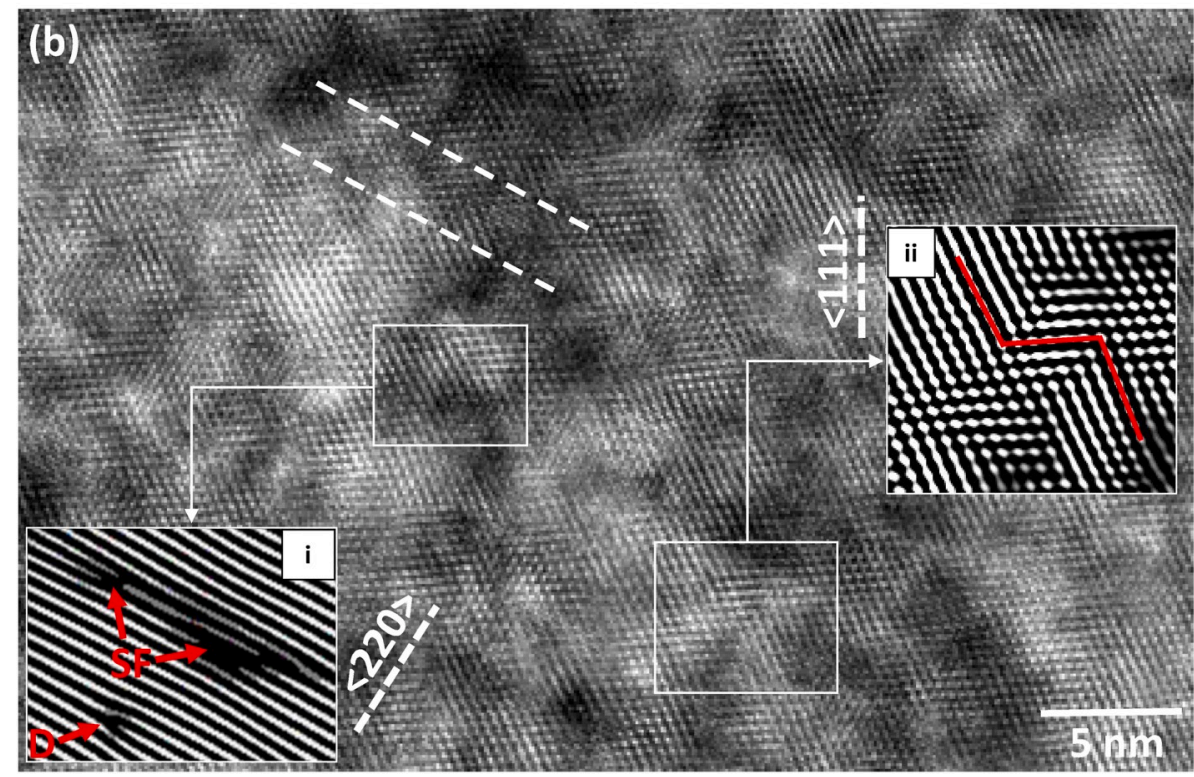

like material lines/planes in deforming matrix, which implies that the magnetic grains set in a matrix undergo rigid body rotation and no intracrystalline deformation. An extreme case of this is the viscous model, where the rigid magnetic grains are considered to be present in a slowly flowing viscous fluid. Both, the line-plane and viscous models have been used to model $\mathrm{P}$ vs. strain relationship for magnetite, where $\mathrm{P}$ increases rapidly with strain for elongated magnetite grains and vice-versa (Hrouda, 1993; Tarling and Hrouda, 1993).

These empirical studies indicate that the deformation mechanism of magnetite has a bearing on rock anisotropy and its relation with strain. However, in all the previous studies dealing with this aspect there has been no visible evidence of ductile behavior of magnetite. The study by Housen et al. (1995) that advocated dislocation creep in magnetite also had no evidence of this. Their correlation between shear strain and $\mathrm{P}$ was empirical and the deformation mechanism map was prepared using the grain size of magnetite from Parry Sound shear zone samples along with theoretical constitutive equations and flow laws following Atkinson (1977). In comparison to the above work, Mamtani et al. (2011) used SEM-EBSD data of magnetite in the Godhra Granite to establish that whilst the matrix minerals (quartz, feldspar and ilmenite) underwent ductile deformation, the magnetite grains remained rigid. Systematic magnetic fabric measurements established an increase in magnetic anisotropy towards a shear zone, which was empirically correlated with strain. A linear correlation between magnetic anisotropy and shape preferred orientation of magnetite grains was established, implying that higher strain led to stronger SPO of magnetite and hence a higher P-value. Since magnetite was shown to have undergone rigid body rotation, and the highest magnetic anisotropy recorded was $\sim 1.5$ (Mamtani et al., 2011), the line-plane model (Hrouda, 1993) is best adapted to the Godhra Granite. This model assumes that the magnetite grains rotate in the rock without undergoing distortion (hence no intracrystalline deformation). However, it maybe noted that in the absence of TEM data, it cannot be unequivocally concluded that the magnetite grains in the Godhra Granite did not undergo any intracrystalline deformation.

In contrast, the present study involves both SEM-EBSD and TEM investigations. We have proved that the elongated magnetite from the Slipsiken Shear Zone has undergone intracrystalline deformation by 

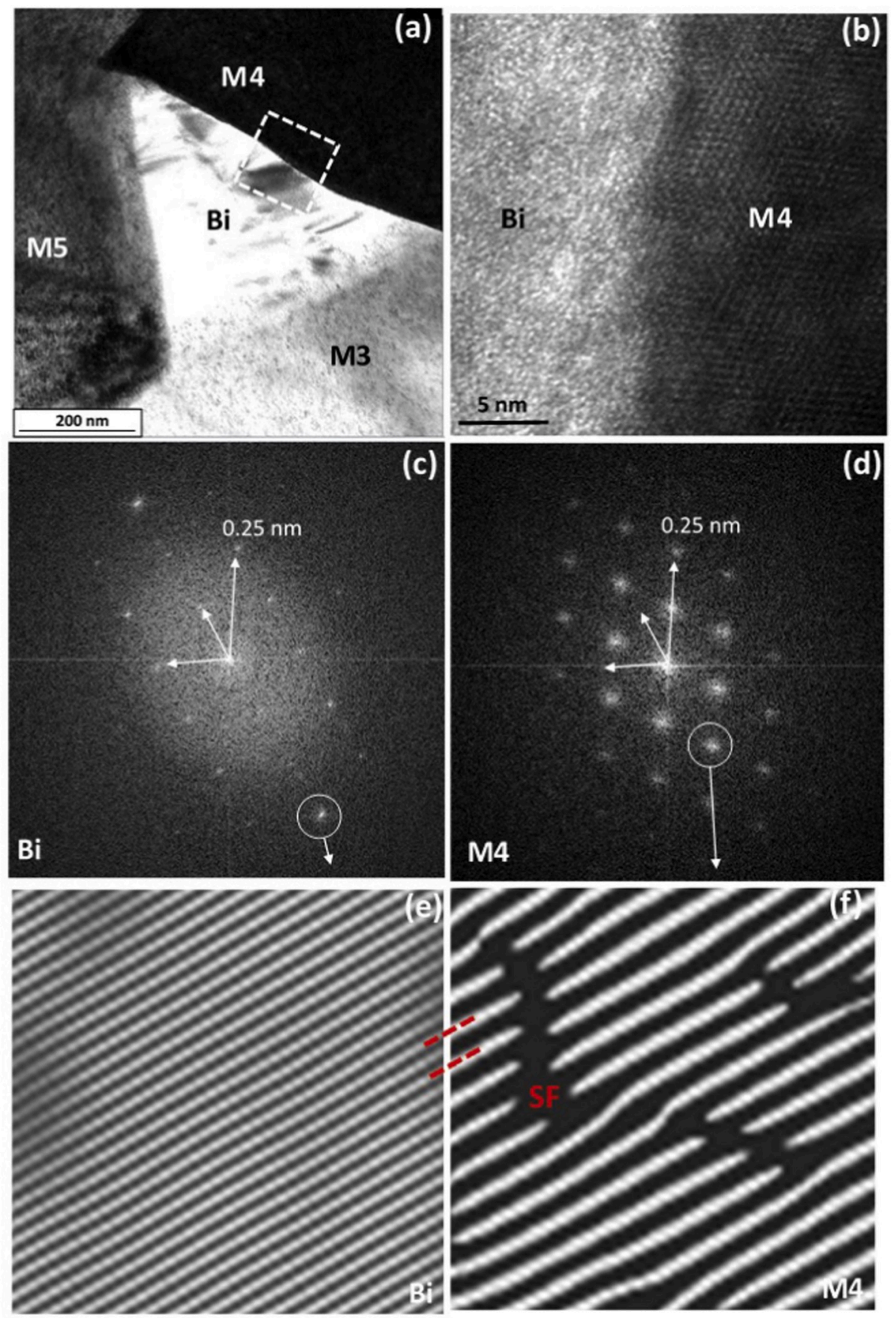

Fig. 9. TEM analysis of magnetite-biotite phase boundary. (a) TEM image showing biotite (Bi) crystal in contact with magnetite (subgrains marked M3, M4, M5). (b) HRTEM image of the M4/Bi phase boundary demarcated in dashed box of (a). Note that this interface (phase boundary) is smooth without significant distortion of atomic planes across it. (c) and (d) are FFT diffractograms taken from biotite (Bi) and magnetite (M4) respectively. In both diffractograms all three selected diffraction vectors (arrows) coincide (see that vectors point at $0.25 \mathrm{~nm}$ distance indicating that atoms in both lattices have the same orientation). (e) is a filtered IFFT image using the (112) reflex of biotite (see circle in (c)). No distortion can be seen. (f) is a filtered IFFT image using the (111) reflex of magnetite (see circle in (d)). The image shows distorted planes (stacking fault marked SF) in magnetite. The dashed lines between (e) and (f) illustrate a coherent, epitaxial intergrowth between magnetite and biotite. dislocation creep. This is in agreement with earlier theoretical and experimental studies advocating dislocation creep in magnetite at medium to high temperature of $>400{ }^{\circ} \mathrm{C}$ (e.g. Housen et al., 1995; Till and Moskowitz, 2013). Ductile deformation is also recognized from petrographic studies of minerals such as quartz and muscovite that surround the magnetite (Fig. 1a). Since both, magnetite and its matrix minerals have undergone intracrystalline deformation, the ductile model described by Hrouda and Lanza (1989) is better suited to explain the P vs. strain relationship in the present study area (also see Hrouda, 1993). The high aspect ratios of magnetite (up to 10.40) and the high P-value $(>3.9)$ in the investigated schist are therefore attributed to strain.

\section{Conclusion}

The present study is an integrated SEM-EBSD and TEM investigation of magnetite hosted in a highly deformed garnet mica schist $\left(\mathrm{T}>550{ }^{\circ} \mathrm{C}\right)$ from the Slipsiken Shear Zone (Sweden). We have proved that the microand nano-structures of magnetite from a naturally deformed rock are due to intracrystalline deformation and are similar to those reported in silicates (e.g. Passchier and Trouw, 2006). The main findings and conclusions are summarized below:

a. The microstructures identified from SEM-EBSD analysis, and the nanostructures identified from TEM imaging prove that the studied magnetite underwent intracrystalline deformation by dislocation creep.

b Translational and rotational Moiré fringes are, respectively, observed at the low angle grain boundary ( $6^{\circ}$ misorientation) and high angle grain boundary $\left(26^{\circ}\right.$ misorientation). 


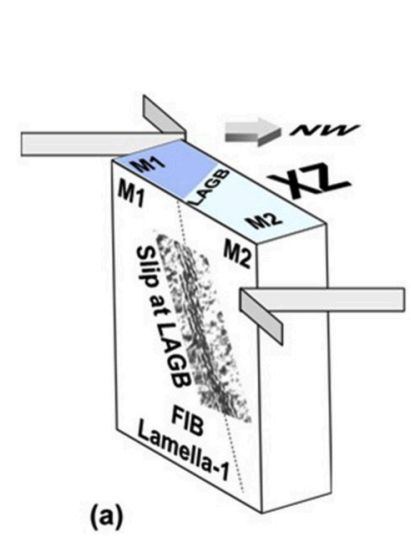

(a)

(b)

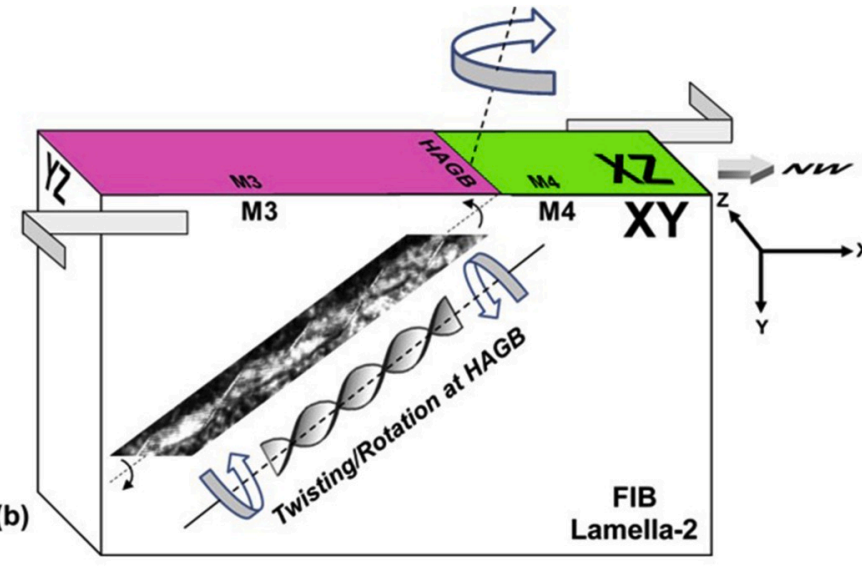

Fig. 10. Schematic representation (not to scale) of the nanotectonic processes prevalent at grain boundaries in magnetite. The diagram helps visualize (3D perspective) the relation between FIB-Lamella orientation, grain boundary on plan view (XZ section), and the nanostructure on the FIB-Lamella in the geographic and tectonic reference frame. (a) Low Angle Grain Boundary (LAGB) at M1/M2 magnetite interface in FIB Lamella-1 showing slip bands and translational Moiré fringes. (b) High Angle Grain Boundary (HAGB) at M3/M4 magnetite interface in FIB Lamella-2, showing rotational Moiré fringes. The latter implies twisting/torsion at HAGB as an important process. Note that the orientation of Lamella-1 and Lamella- 2 is oblique and parallel to the XY plane of strain ellipsoid, respectively (compare with Fig. 4). The kinematics in the geographical reference frame fits well with the twisting/torsional/ rotational movement at the HAGB that results in the helix geometry of the Moiré fringes. c The orientation of grain boundaries and the sense of translation/ rotation along them at the nanoscale (HRTEM imaging) are kinematically compatible with the regional sense of shear (top-to-NW in Slipsiken Shear Zone). Although we have performed TEM investigation of two FIB lamellae in this study, the present approach is unique, because the orientation of these lamellae in the regional tectonic framework is known. Hence, this study provides a modus operandi to evaluate nanotectonics and relate the evolution of nanostructures to large scale tectonics and kinematics.

d The elongated shape of magnetite in the schist under study results from its ductile behavior. This influences the magnetic properties and results in a high degree of magnetic anisotropy. Thus, caution needs to be exercised while considering rigid body rotation as the exclusive behavior of magnetite in petrofabric studies and to explain the magnetic anisotropy vs. strain relationship.

e The presence of biotite nanocrystal intergrown epitaxially with magnetite in our sample points to the possible role of fluids in deformation of magnetite by dislocation creep. However, the role of wet versus dry deformation, and the influence of strain rate on the intracrystalline deformation of magnetite and its relationship to AMS, obviously need complementary studies.

\section{Declaration of competing interest}

The authors declare that they have no known competing financial interests or personal relationships that could have appeared to influence the work reported in this paper.

\section{CRediT authorship contribution statement}

Manish A. Mamtani: Data curation, Formal analysis, Writing original draft, Conceptualization, Methodology. Boris Reznik: Data curation, Formal analysis, Conceptualization, Methodology. Agnes Kontny: Conceptualization, Writing - review \& editing.

\section{Acknowledgments}

MAM thanks the Alexander von Humboldt Foundation for supporting his research stay in KIT Karlsruhe (Germany) in 2017 (AvH Alumni Program) during which this study was conceived and sample selection was done. Amarnath Dandapat (Department of Geology and Geophysics, IIT Kharagpur, India) is thanked for preparing well-polished samples for
EBSD analysis. Thanks are due to B. Santu Mudliyar and Niloy Bhowmik (Central Research Facility, IIT Kharagpur) for helping with SEM and EBSD analysis, respectively. Abhijit Viswanathan, Shalini Goswami, Abhijeet Suryawanshi and Tuhin Chakraborty helped at various stages of imaging and data processing in the Department of Geology and Geophysics, IIT Kharagpur. TEM studies were carried out in the Laboratory for Electron Microscopy (LEM) at KIT (Germany) during MAM's research stay in Karlsruhe in 2019 that was facilitated by a DAAD Scholarship (Re-invitation Alumni Program). Erich Müller and Heike Stormer of LEM (KIT, Karlsruhe) are thanked for FIB lamella preparation and TEM imaging, respectively. The sample investigated was collected during a field campaign in 2005 by Jens C. Grimmer (KIT, Karlsruhe), and we highly appreciate the sharing of samples and discussions with him on the Slipsiken Shear Zone. Reviews by Jean-Luc Bouchez and František Hrouda, and editorial handling by Ian Alsop are gratefully acknowledged.

\section{References}

Archanjo, C.J., Launeau, P., Bouchez, J.L., 1995. Bulk magnetic fabric versus shape fabrics of magnetite and biotite in magnetite-bearing pluton (Gameleiras, Northeast Brazil). Phys. Earth Planet. In 89, 63-75.

Atkinson, B.K., 1977. The kinetics of ore deformation: its illustration and analysis by means of deformation-mechanism maps. Geologiska Foreningens Forhandlingar 99, 186-197.

Banfield, J.F., Wasilcwski, P.J., Vebken, D.R., 1994. TEM study of relationships between the microstructures and magnetic properties of strongly magnetised magnetite and maghemite. Am. Mineral. 79, 654-667.

Borradaile, G.J., Henry, B., 1997. Tectonic applications of magnetic susceptibility and its anisotropy. Earth Sci. Rev. 42, 49-93.

Borradaile, G.J., Jackson, M.J., 2010. Structural geology, petrofabrics and magnetic fabrics (AMS, AARM, AIRM). J. Struct. Geol. 32, 1519-1551.

Bouchez, J.-L., 1997. Granite is never isotropic: an introduction to AMS studies of granitic rocks. In: Bouchez, J.L., Hutton, D.W.H., Stephens, W.E. (Eds.), Granite: from Segregation of Melt to Emplacement Fabrics. Kluwer Acad. Publ., Dordrecht, The Netherlands, pp. 95-112.

Carreras, J., 2001. Zooming on northern cap de Creus shear zones. J. Struct. Geol. 23, 1457-1486.

Ferré, E., Teyssier, C., Jackson, M., Thill, J.W., Rainey, E.S.G., 2003. Magnetic susceptibility anisotropy: a new petrofabric tool in migmatites. J. Geophys. Res. 108 (B2), 2086. https://doi.org/10.1029/2002JB001790.

Graham, J.W., 1954. Magnetic susceptibility anisotropy, an unexploited petrofabric element. Bull. Geol. Soc. Am. 65, 1257-1258. 
Grimmer, J.C., Glodny, J., Drüppel, K., Greiling, R.O., Kontny, A.M., 2015. Early- to midSilurian extrusion wedge tectonics in the central Scandinavian Caledonides. Geology 43, 347-350.

Heaney, P.J., Vicenzi, E.P., Giannuzzi, L.A., Livi, K.J.T., 2001. Focused ion beam milling: a method of site-specific sample extraction for microanalysis of Earth and planetary materials. Am. Mineral. 86, 1094-1099.

Hennig-Michaeli, C., Siemes, H., 1975. Zwillingsgleitung beim magnetit. Neues Jahrbuch Mineral. Abhand. 123, 330-334.

Hennig-Michaeli, C., Siemes, H., 1982. Compression experiments on natural magnetite crystals at $200{ }^{\circ} \mathrm{C}$ and $400{ }^{\circ} \mathrm{C}$ at $400 \mathrm{MPa}$ confining pressure. In: Issues in Rock Mechanics Proceedings, Twenty-Third Symposium on Rock Mechanics, the University of California. Society of Mining Engineers of AIME, New York, NY, p. 380. Berkeley, California, August 25-27, 1982.

Hernandez-Moreno, C., Speranza, F., Di Chiara, A., 2014. Understanding kinematics of intra-arc transcurrent deformation: paleomagnetic evidence from the Liquine-Ofqui fault zone (Chile, $38-41^{\circ}$ S). Tectonics 33, 1964-1988.

Hillier, J., 1954. New Interference Phenomena in the Electron Microscopic Images of Plate-like Crystals, 527. National Bureau of Standards, pp. 413-416.

Housen, B.A., van der Pluijm, B.A., Essene, E.J., 1995. Plastic behaviour of magnetite and high strains obtained from magnetic fabrics in the Parry Sound shear zone, Ontario Grenville Province. J. Struct. Geol. 17, 265-278.

Hrouda, F., 1993. Theoretical models of magnetic anisotropy to strain relationship revisited. Phys. Earth Planet. In. 77, 237-249.

Hrouda, F., Lanza, R., 1989. Magnetic fabric in the Biella and Traversella stocks (Periadriatic Line): implications for the emplacement mode. Phys. Earth Planet. In. 56, 337-348.

Kontny, A., Engelmann, R., Grimmer, J.C., Greiling, R.O., Hirt, A., 2012. Magnetic fabric development in a highly anisotropic magnetite-bearing ductile shear zone (Seve Nappe Complex, Scandinavian Caledonides). Int. J. Earth Sci. 101, 671-692.

Lindquist, A., Feinberg, J., Harrison, R., Loudon, J., Newell, A., 2015. Domain wall pinning and dislocations: investigating magnetite deformed under conditions analogous to nature using transmission electron microscopy. J. Geophys. Res. 120, 1415-1430.

Lindquist, A.K., Feinberg, J.M., Harrison, R.J., Loudon, J.C., Newell, A.J., 2019. The effects of dislocations on crystallographic twins and domain wall motion in magnetite at the Verwey transition. Earth Planets Space 71, 5.

Majumder, S., Mamtani, M.A., 2009. Magnetic fabric in the malanjkhand granite (Central India) - implications for regional tectonics and proterozoic suturing of the Indian shield. Phys. Earth Planet. In. 172, 310-323.

Mamtani, M.A., 2012. Fractal analysis of magnetite grains - implications for interpreting deformation mechanism. J. Geol. Soc. India 80, 308-313.

Mamtani, M.A., 2014. Magnetic fabric as a vorticity gauge in syntectonically deformed granitic rocks. Tectonophysics $629,189-196$.

Mamtani, M.A., Greiling, R.O., 2005. Granite emplacement and its relation with regional deformation in the Aravalli Mountain Belt (India) - inferences from magnetic fabric. J. Struct. Geol. 27, 2008-2029.

Mamtani, M.A., Greiling, R.O., 2010. Serrated quartz grain boundaries, temperature and strain rate: testing fractal techniques in a syntectonic granite. In: Spalla, I., Marotta, A.M., Gosso, G. (Eds.), Advances in Interpretation of Geological Processes:
Refinement of Multi-Scale Data and Integration in Numerical Modelling, 332. Geological Society, London, Special Publications, pp. 35-48.

Mamtani, M.A., Piazolo, S., Kontny, A., Greiling, R.O., Hrouda, F., 2011. Process of magnetite fabric development during granite deformation. Earth Planet Sci. Lett. 308, 77-89.

McLaren, A.C., 1991. Transmission Electron Microscopy of Minerals and Rocks. Cambridge University Press, New York.

Merz, L., Almqvist, B., Grimmer, J., Kontny, A., 2019. Magnetic fabric development in the Lower Seve thrust from the COSC-1 drilling, Swedish Caledonides. Tectonophysics 751, 212-228.

Mitsuishi, T., Nagasaki, H., Uyeda, R., 1951. A new type of interference fringes observed in electron-micrographs of crystalline substance. Proc. Jpn. Acad. 27, 86-87.

Müller, P., Siemes, H., 1972. Zur Festigkeit und Gefügeregelung von experimentell verformten Magnetiterzen (Strength and preferred orientation of experimentally deformed magnetite ores). Neues Jahrbuch Mineral. Abhand. 117, 39-60.

Nicolas, A., Poirier, J.P., 1976. Crystalline Plasticity and Solid State Flow in Metamorphic Rocks. Wiley, New York.

Owens, W.H., 1974. Mathematical model studies on factors affecting the magnetic anisotropy of deformed rocks. Tectonophysics $24,115-131$.

Passchier, C.W., Trouw, R.A.J., 2006. Microtectonics. Springer, Berlin.

Platt, J.P., Becker, T.W., 2013. Kinematics of rotating panels of E-W faults in the San Andreas system: what can we tell from geodesy? Geophys. J. Int. 194, 1295-1301.

Reznik, B., Kontny, A., Fritz, J., Gerhards, U., 2016. Shock- induced deformation phenomena in magnetite and their consequences on magnetic properties. G-cubed $17,1-20$.

Schenk, O., Urai, J.L., 2004. Microstructural evolution and grain boundary structure during static recrystallization in synthetic polycrystals of sodium chloride containing saturated brine. Contrib. Mineral. Petrol. 146, 671-682.

Sen, K, Majumder, S, Mamtani A, M, 2005. Degree of magnetic anisotropy as a strain intensity gauge in ferromagnetic granites. J. Geol. Soc. (Lond.) 162, 583-586. https://doi.org/10.1144/0016-764904-144.

Sen, K., Mamtani, M.A., 2006. Magnetic fabric, shape preferred orientation and regional strain in granitic rocks. J. Struct. Geol. 28, 1870-1882.

Sitzman, S.D., Banfield, J.F., Valley, J.W., 2000. Microstructural characterization of metamorphic magnetite crystals with implications for oxygen isotope distribution. Am. Mineral. 85, 14-21.

Spry, A., 1969. Metamorphic Textures. Pergamon Press, Oxford.

Tarling, D.H., Hrouda, F., 1993. The Magnetic Anisotropy of Rocks. Chapman and Hall, London.

Till, J.L., Moskowitz, B., 2013. Magnetite deformation mechanism maps for better prediction of strain partitioning. Geophys. Res. Lett. 40, 697-702.

Till, J.L., Moskowitz, B.M., 2014. Deformation microstructures and magnetite texture development in synthetic shear zones. Tectonophysics 629, 211-223.

Till, J.L., Moskowitz, B.M., Jackson, M.J., 2012. High-temperature magnetic fabric development from plastically deformed magnetite in experimental shear zones. Geophys. J. Int. 189, 229-239.

Williams, D.B., Carter, C.B., 2009. Transmission Electron Microscopy - A Textbook for Materials Science, second ed. Springer. 
Karlsruher Institut für Technologie

\section{Repository KITopen}

Dies ist ein Postprint/begutachtetes Manuskript.

Empfohlene Zitierung:

Mamtani, M. A.; Reznik, B.; Kontny, A.

Intracrystalline deformation and nanotectonic processes in magnetite from a naturally deformed rock. 2020. Journal of structural geology, 135.

doi: $\underline{10.5445 / / R / 1000118177}$

Zitierung der Originalveröffentlichung:

Mamtani, M. A.; Reznik, B.; Kontny, A.

Intracrystalline deformation and nanotectonic processes in magnetite from a naturally deformed rock.

2020. Journal of structural geology, 135, 104045.

doi: $\underline{10.1016 / j . j s g .2020 .104045}$ 